12. Kameoka K, Oka Y, Mitsuhashi T, et al. (1994) Mitochondrial DNA mutation in autoimmune thyroid diseases. Folia Endocrinologica Japonica 70: 219-N1-57 (Abstract in Japanese)

13. Yanagisawa K, Uchigata Y, Sanaka M, et al. (1995) Mutation in the mitochondrial tRNA-leu at position 3243 and spontaneous abortions in Japanese women attending a clinic for diabetic pregnancies. Diabetologia 38: 809-815
14. Maasen JA, Kadowaki T (1996) Maternally inherited diabetes and deafness: a new diabetes subtype. Diabetologia 39: $375-382$

15. Kishimoto M, Hashiramoto M, Araki S, et al. (1995) Diabetes mellitus carrying a mutation in the mitochondrial tRNA-Leu(UUR) gene. Diabetologia 38: 193-200

16. Kadowaki T, Kadowaki H, Mori Y, et al. (1994) A subtype of diabetes mellitus associated with a mutation of mitochondrial DNA. N Engl J Med 330: 962-968

\section{Response from the authors}

\section{Dear Sir,}

We read with interest the comment by Drs. Odawara and Yamashita claiming a minor contribution of the mitochondrial DNA mutation at 3243 bp (A to G) (mtDNA 3243 mutation) to the aetiology of autoimmune insulin-dependent diabetes mellitus (IDDM). We would like to emphasize that a high proportion of diabetic patients with the mtDNA 3243 mutation have cytoplasmic islet cell antibodies (ICA) and an IDDM-related HLA-DQ allele [1]. Our diabetic patients with mtDNA 3243 mutation included subjects with various clinical phenotypes of diabetes ranging from non-insulin-dependent diabetes (NIDDM) to IDDM [1]. The prevalence of mtDNA 3243 mutation is not high in IDDM patients, ranging from 0 to $11 \%[2-4]$. Thus, one cannot simply extrapolate from our results to a general conclusion that the mtDNA 3243 mutation forms a background for beta-cell destruction in a majority of IDDM patients. However, fasting serum Cpeptide levels were less than $0.17 \mathrm{nmol} / 1$ in 3 of 16 insulintreated diabetic patients in our previous report [1], indicating that some of them actually had IDDM. A closer relationship between the mtDNA 3243 mutation and ICA was confirmed in Japanese and Caucasian populations [5, 6]. Oexle et al. [6] reported the presence of ICA in an extremely insulin-deficient diabetic mother (10 JDF units), and her son had impaired glucose tolerance (80 JDF units). They had at least one HLA-DQ allele associated with IDDM. Apparently, it is still premature to conclude that the presence of pancreatic autoantibodies in diabetic patients with the mtDNA $3243 \mathrm{mu}-$ tation is a secondary consequence rather than a cause of betacell destruction. B lymphocyte mediated factor is essential in the development of autoimmune NOD mice [7]. It is generally assumed that IDDM is a heterogenous disease in which multiple loci and other factors influence the initiation and progression of beta-cell failure through immunological, viral and/or chemical mechanisms in an additive manner $[8,9]$. In this context, mtDNA 3243 mutation constitutes one distinct genetic background for IDDM, even if a minor proportion of IDDM patients have this mutation.

The relationships among the mtDNA 3243 mutation, pancreatic autoimmunity and beta-cell destruction may be clarified by analysing the pancreas in diabetic patients with the mutation.

Corresponding author: T. Kobayashi, M. D., Department of Endocrinology and Metabolism, Toranomon Hospital, 2-2-2, Toranomon, Minato-ku, Tokyo 105, Japan
We examined histological changes in the autopsied pancreases of 16 IDDM patients and 18 NIDDM patients [10]. One of 16 (6\%) IDDM pancreases had a high proportion of islet cells with mtDNA 3243 mutation, as well as some exocrine cells. We found beta-cells to be reduced along with decreased mitochondrial DNA-encoded enzyme related oxidative phosphorylation (OXPHOS): cytochrome c oxidase (COX), as well as enhanced nuclear-encoded enzyme related OXPHOS: succinate dehydrogenase $(\mathrm{SDH})$ in the affected pancreas. Hyperexpressed SDH (complex II) activity in the islet cells may accelerate damage to beta-cells through increased toxic hydroxyl radicals generated from the accelerated electron transport system via the enhanced complex II pathway, which generates four times more mitochondrial superoxide than electrons channelled via the complex I pathway [11]. DNA damage in beta cells due to toxic hydroxyl radicals is assumed to be a possible cause of IDDM [12]. CD8 ${ }^{+}$lymphocyte infiltration around the islets as well as pancreatic exocrine cells was also observed in the pancreas with the mutation.

In conclusion, pathological features in the pancreas of diabetic patients with the mitochondrial DNA mutation as well as humoral markers represented by ICA may provide new insights into the mechanisms of beta-cell destruction in at least one distinct clinical phenotype of IDDM.

Yours sincerely,

T. Kobayashi, K. Nakanishi, T. Murase

\section{References}

1. Kobayashi T, Oka Y, Katagiri H et al. (1996) Association between HLA and islet cell antibodies in diabetic patients with a mitochondrial DNA mutation at base pair 3243. Diabetologia 39: 1196-1200

2. Odawara M, Sasaki K, Yamashita K (1995) Prevalence and clinical characterization of Japanese diabetes mellitus with an A to $\mathrm{G}$ mutation at nucleotide 3243 of the mitochondrial tRNA-Leu (UUR) gene. J Clin Endocrinol Metab 80: 1290-1294

3. Kadowaki T, Kadowaki H, Mori Y, et al. (1994) A subtype of diabetes mellitus associated with a mutation of mitochondrial DNA. N Engl J Med 330: 962-968

4. Oka Y, Katagiri H, Yazaki Yet al. (1993) Mitochondrial gene mutation in islet-cell-antibody-positive patients whowere initially non-insulin-dependent diabetics. Lancet 342: 527-528

5. Taniyama M, Kasuga A, Suzuki Y et al. (1997) Absence of antibodies to ICA512/IA-2 in NIDDM patients with the mitochondrial DNA bp 3243 mutation. Diabetes Care 20: 905-906 
6. Oexle K, Oberle J, Finckh B et al. (1996) Islet cell antibodies in diabetes mellitus associated with a mitochondrial tRNA $^{\text {leu(UUR) }}$ gene mutation. Exp Clin Endocrinol Diabetes 104: 212-217

7. Serreze DV, Chapman HD, Varnu DS et al. (1996) B lymphocytes are essential for the initiation of T cell-mediated autoimmune diabetes: analysis of a new "speed congenic" stock of NOD.Ig $\mu^{\text {null }}$ mice. J Exp Med 184: 20492053

8. Atkinson MA, Maclaren NK (1994) The pathogenesis of insulin-dependent diabetes mellitus. N Engl J Med 331: 1428-1436

9. Degli Esposti M, Ngo A, Myers MA (1996) Inhibition of mitochondrial complex I may account for IDDM induced by intoxication with the rodenticide vacor. Diabetes 45 : 1531-1534

10. Kobayashi T, Nakanishi K, Nakase H et al. (1997) In situ characterization of islets in diabetes with a mitochondrial DNA mutation at nucleotide position 3243. Diabetes, in press (October issue)

11. Cortopassi G, Wang E (1995) Modelling the effects of agerelated mtDNA mutation accumulation; complex I deficiency, superoxide and cell death. Biochem Biophys Acta 1271: $171-176$

12. Okamoto $H$ (1993) The molecular basis of experimental diabetes. In: Okamoto $\mathrm{H}$ (ed) The molecular biology of the islets of Langerhans. Cambridge University Press, Cambridge, pp 209-231 